ARTIGO

\title{
Educação, autoridade e razão: possibilidades de crítica à perspectiva hermenêutica
}

Rainri Back' (D)

RESUMO

Este ensaio divide-se em três partes. Primeiro, apresenta as críticas de Gadamer contra a ideia de autoridade do Iluminismo. Depois, expõe as críticas de Habermas contra Gadamer. Por fim, contrapõe as respostas de Gadamer às críticas de Habermas. Aqui, interessa apenas as implicações do conceito de autoridade para a educação. Este ensaio não trata do debate geral entre Habermas e Gadamer. A finalidade é pensar sobre como, na educação, a autoridade influi sobre a razão. Para tanto, parte de uma pressuposição: uma boa educação visa estimular a liberdade da razão. Eis o problema: a autoridade não coíbe a liberdade da razão, fim de uma boa educação?

PALAVRAS-CHAVE

autoridade; pessoa; tradição; razão; educação.

'Universidade de Brasília, Brasília, DF, Brasil. 


\title{
EDUCATION, AUTHORITY AND REASON: POSSIBILITIES OF CRITICISM TO THE HERMENEUTIC POINT OF VIEW
}

\begin{abstract}
This essay is divided into three parts. First, it presents Gadamer's criticisms against the idea of Enlightenment authority. Then it exposes the criticisms of Habermas against Gadamer. Finally, it counters Gadamer's responses to Habermas's criticisms. Here only the implications of the concept of authority for education are concerned. This essay will not deal with the general debate between Habermas and Gadamer. Its purpose is to think about how, in education, authority influences reason. Therefore, it presumes that a good education aims to stimulate the freedom of reason. Hence, the problem is: doesn't authority restrain the freedom of reason, the very end of a good education?
\end{abstract}

\section{KEYWORDS}

authority; person; tradition; reason; education.

\section{EDUCACIÓN, AUTORIDAD Y RAZÓN: POSIBILIDADES DE CRÍTICA DESDE LA PERSPECTIVA HERMENÉUTICA}

\section{RESUMEN}

Este ensayo se divide en tres partes. Primero, presenta las críticas de $\mathrm{Ga}-$ damer a la idea de autoridad de la Ilustración. Luego, expone las críticas de Habermas contra Gadamer. Finalmente, contrasta las respuestas de $\mathrm{Ga}-$ damer a las críticas de Habermas. Aquí, solo conciernen las implicaciones del concepto de autoridad para la educación. Este ensayo no abordará el debate general entre Habermas y Gadamer. El propósito es pensar cómo, en la educación, la autoridad influye en la razón. Por lo tanto, parte de una presuposición: una buena educación tiene como objetivo estimular la libertad de razón. Aquí está el problema: cla autoridad no restringe la libertad de la razón, el fin de una buena educación?

PALABRAS CLAVE

autoridad; persona; tradición; razón; educación. 


\section{ONDE COMEÇA O DEBATE ENTRE HABERMAS E GADAMER}

Boa parte da discussão de Habermas com Gadamer se concentra no modo como compreensão e método se relacionam e nas possíveis consequências extraídas dessa relação. Como tal discussão se relaciona com a educação? Habermas a desenvolve até se deter em um exemplo de Gadamer sobre a autoridade do educador. Então ele examina como a "consciência dos efeitos da história" repercute sobre a relação entre autoridade e razão. Ora, quem educa invariavelmente acaba transmitindo uma tradição. Logo, precisa-se lidar com os efeitos históricos que essa tradição exerce sobre si e os outros. Assim, a educação está no ponto de cruzamento entre tradição, autoridade e razão; ponto estratégico para saber se tradição e autoridade sufocam a razão.

Pois bem. Onde se origina o problema? Para Habermas, Gadamer subestima a importância da metodologia para as ciências humanas. Gadamer parte da pressuposição segundo a qual o que a move, a compreensão, não pode ser metodizado. Ao contrapor a verdade ao método, Gadamer teria sido induzido a "contrapor abstratamente" a experiência hermenêutica e o conhecimento. Porém, há um equívoco aí, o filósofo alemão argumenta, porque as ciências humanas não podem ignorar a exigência de relacionar hermenêutica e "procedimentos empírico-analíticos". Não seria possível livrar as ciências humanas do problema do método, nem mesmo se elas representassem uma exceção à pretensão de universalidade dos métodos das ciências experimentais.

Para Gadamer, na interpretação de Habermas (1990), os procedimentos metodológicos da ciência obscurecem a "substância natural da tradição" ao transformá-la em objeto a ser constatado. Tais procedimentos acabam sugerindo um falso distanciamento em relação à tradição, quando, na verdade, ela é o ponto onde se fundem as "tradições ainda viventes" e a "pesquisa hermenêutica". Habermas discorda porque Gadamer parte de uma pressuposição equivocada: a "reflexão científica" deturparia o vínculo estrutural da compreensão com a tradição. Para Habermas, ocorre o contrário, a "formação metodológica da inteligência" pode alterar somente uma coisa: o "equilíbrio entre autoridade e razão". Assim, Habermas chega ao problema da autoridade.

Este artigo se propõe a examinar o debate de Habermas e Gadamer sobre o conceito de autoridade. Assim, são trabalhados os textos nos quais Habermas expõe suas críticas ao que Gadamer compreende por autoridade e nos quais Gadamer responde a Habermas. Mais especificamente, a este ensaio interessa apenas os exemplos nos quais ambos os filósofos apontam para as implicações da autoridade para a educação. Então, o artigo se concentra em $A$ lógica das ciências sociais e nos dois volumes de Verdade e método. No entanto, não aborda o debate geral entre Habermas e Gadamer; em particular, as críticas de Habermas à suposta universalidade do problema hermenêutico. Interessa apenas as implicações do conceito de autoridade para a educação.

\section{O QUE É AUTORIDADE, SEGUNDO GADAMER}

As críticas de Habermas a Gadamer se concentram, basicamente, em uma discussão sobre o que significa autoridade. Mais especificamente, incidem sobre o esforço de Gadamer para reabilitar a palavra "preconceito" do descrédito sofrido desde a época do Iluminismo. Para tanto, Gadamer considera necessário submeter 
à crítica o que o Iluminismo compreendeu por autoridade e tradição. Nesse aspecto se inicia a polêmica com Habermas. Há vários pontos de discordância entre os filósofos, de sorte que, para organizar a exposição, primeiro, parece melhor expor as ideias de Gadamer. Assim, esta primeira seção se propõe a compreender por que, para o filósofo, autoridade e razão não se excluem mutuamente, ao contrário do que supõe o Iluminismo.

Descartes legou ao Iluminismo [Aufklärung], segundo Gadamer (2003, p. 368-370), uma pressuposição fundamental. Para se proteger de qualquer erro, recomenda Descartes, basta exercitar disciplinada e metodicamente, a razão. Em geral, há basicamente duas fontes de equívoco: a autoridade e a precipitação. Enquanto a precipitação é um erro cometido no exercício da razão, a autoridade, ao contrário, induz ao erro, porque coíbe a razão. Assim, a diferença entre ambas denuncia a oposição excludente entre autoridade e razão, cuja consequência é a desconfiança quanto ao que a tradição consagrou. Portanto, contra qualquer ordem imposta, seria necessário inverter os papeis e "submeter toda autoridade à razão" (Gadamer, 2003, p. 369).

A princípio, Gadamer (2003, p. 370) reconhece o quinhão de sensatez da Aufklärung quando opõe "fé na autoridade e uso da própria razão". De fato, a autoridade seria mesmo fonte de preconceitos, se sua afirmação se baseasse na coibição da capacidade de alguém avaliá-la por si próprio. Porém, tal concessão à Aufklärung não contradiz a possibilidade de a autoridade "ser também uma fonte de verdade" (Gadamer, 2003, p. 370). Em outras palavras, entre autoridade e razão não há qualquer oposição que possa torná-las mutuamente excludentes. Eis o preconceito da Aufklärung! Ao exclui-la do âmbito da razão, a Aufklärung deformou a ideia de autoridade a ponto de defini-la como "obediência cega", o que se consolidou na crítica às ditaduras modernas.

Então, como ambas, autoridade e razão, podem coerir entre si? Ao invés de "obediência cega", segundo Gadamer (2003, p. 371), a autoridade é, primeiramente, "uma atribuição a pessoas". A autoridade de uma pessoa, argumentou Gadamer, não se funda na submissão, na "abdicação da razão", mas, sim, requer o reconhecimento segundo o qual alguém só detém autoridade porque dispõe de mais conhecimento sobre certas coisas. Assim, se alguém pretende ser reconhecido como autoridade, não deve esperar adquiri-la por outorga; a autoridade "deve ser alcançada". Logo, ao requerer reconhecimento, a autoridade se baseia em uma ação racional. Ciente de sua falta de conhecimento, uma pessoa reconhece em outra "uma visão mais acertada" sobre certo assunto. Portanto, a autoridade não depende da submissão, da obediência cega, mas da aquisição de um conhecimento socialmente reconhecido.

Nesse ponto, Gadamer não almeja apenas apresentar outra maneira de compreender a autoridade. Antes, ele pretende recuperar o que deveria ser considerado a essência desse conceito. Na sequência, o filósofo (Gadamer, 2003, p. 371) desenvolve breves considerações sobre a relação entre autoridade e obediência. $\mathrm{O}$ senso comum tende a compreender a autoridade como uma espécie de índole para impor obediência, de iniciativa espontânea para emitir ordens. Para Gadamer, ao contrário, só faz sentido obedecer às ordens de alguém 
reconhecidamente dotado do conhecimento necessário para dá-las. Em suma, a autoridade envolve, sim, o poder de emitir ordens e esperar obediência. Entretanto, não decorre de tal poder; ao contrário, a autoridade é o que o torna possível. Só emite ordens quem "sabe melhor" e, assim, conquista a autoridade para emiti-las. Por conseguinte, até mesmo a obediência a uma autoridade deve se fundar em um reconhecimento racional. Gadamer pretende refutar, assim, a incompatibilidade entre autoridade e razão.

Ora, o que Gadamer defende, em geral, sobre autoridade e obediência deve valer, por óbvio, para qualquer caso particular, como, por exemplo, a autoridade de um educador. Eis, portanto, a primeira relação entre educação, autoridade e razão! A autoridade de um educador se assenta no reconhecimento livre e racional de quem ele educa como alguém mais sábio. É o que o filósofo defende na passagem seguinte:

É assim que o reconhecimento da autoridade está sempre ligado à ideia de que o que a autoridade diz não é uma arbitrariedade irracional mas algo que em princípio pode ser compreendido. É nisso que consiste a essência da autoridade que exige o educador, o superior, o especialista. É claro que os preconceitos que eles inculcam encontram-se legitimados pela pessoa. Sua validez requer predisposição para com a pessoa que os representa. Mas é exatamente assim que se convertem em preconceitos objetivos, pois operam a mesma predisposição para com uma coisa, que pode se estabelecer por outros caminhos, por exemplo, por bons motivos validados pela razão (Gadamer, 2003, p. 371-372, grifos do autor).

Até este ponto da discussão, o esforço de Gadamer para recuperar a essência perdida da autoridade se restringiu, especificamente, à autoridade de uma pessoa. Como o filósofo mesmo observou: "[...] a autoridade é, em primeiro lugar, uma atribuição a pessoas" (Gadamer, 2003, p. 371). Então, Gadamer passa a outra espécie de autoridade: a tradição. Entretanto, o filósofo não aborda rigorosamente a diferença entre ambos os modos de autoridade. Mas é importante atentar para tal diferença, porque, em um debate, pode ser fácil incorrer em certo erro lógico. É possível defender Gadamer de críticas à autoridade da pessoa, por exemplo, mas fracassar ao defendê-lo de críticas à autoridade da tradição. Se uma não deve ser confundida com outra, é fundamental pontuar a mudança de assunto na exposição de Gadamer.

Gadamer passa a tratar de outra forma de autoridade quando retoma as críticas do Romantismo à Aufklärung ${ }^{1}$. Segundo ele (Gadamer, 2003, p. 372), o

1 "Para isso podemos nos apoiar na crítica que o romantismo faz à Aufklärung, pois existe uma forma de autoridade que foi particularmente defendida pelo romantismo: a tradição. O que é consagrado pela tradição e pela herança histórica possui uma autoridade que se tornou anônima, e nosso ser histórico e finito está determinado pelo fato de que, também a autoridade do que foi transmitido, e não somente o que possui fundamentos evidentes, tem poder sobre nossa ação e nosso comportamento" (Gadamer, 2003, p. 372). 
Romantismo defendeu uma forma particular de autoridade: a tradição. Uma peculiaridade da autoridade da tradição reside no fato de ser "anônima", como nota Gadamer, ao contrário da autoridade de uma pessoa. Decerto, é possível acatar as ordens de alguém, como, por exemplo, de um líder revolucionário, cujo nome, por segurança, deve ser mantido em segredo. Mas uma tradição é anônima em outro sentido bem diferente. No caso de um líder revolucionário, há alguém de quem outros esperam orientações sobre como agir. Já no caso de uma tradição, ninguém em particular responde em seu nome. Assim se manifesta o anonimato da autoridade da tradição, segundo Gadamer.

Na sequência da exposição, mais uma vez, Gadamer recorre ao exemplo da educação para demonstrar a afinidade entre razão e autoridade. Antes, dada a amplitude bem menor do fenômeno da autoridade de uma pessoa, Gadamer se ateve à relação particular entre professor e estudante. Agora, ante um fenômeno com amplitude bem maior, a autoridade da tradição, ele passa se referir à educação em geral. Aqui, Gadamer sugere algo digno de atenção: amadurecer a ponto de se libertar da autoridade de professores não significa libertar-se de qualquer autoridade. Há ainda a autoridade da tradição, da qual não lhe parece possível se livrar. Portanto, não haveria alternativa para a razão, senão se conciliar, de alguma maneira, com a autoridade:

[...] Toda educação repousa sobre essa base e, mesmo no caso em que se alcança um estágio na educação quando a 'tutela' perde a sua função com o amadurecimento gerado pela maioridade, momento em que as próprias perspectivas e decisões assumem finalmente a posição que detinha a autoridade do educador, esta chegada da maturidade na história de vida não implica, de modo algum, que nos tornemos senhores de nós mesmos no sentido de havermos nos libertado de toda herança histórica e de toda tradição (Gadamer, 2003, p. 372).

Ora, se é assim, então como a tradição se impõe, enquanto autoridade, sem coibir o exercício da razão? Para responder tal questionamento, Gadamer parte, a princípio, de críticas do Romantismo à Aufklärung. "A realidade dos costumes", diz o filósofo (Gadamer, 2003, p. 372) em nome do Romantismo, deve sua validez à tradição. A adoção de costumes também ocorre livremente, mas sua validade se deve a uma liberdade particular, distinta do livre discernimento. $\mathrm{O}$ que a tradição transmite, no caso em apreço, os costumes, apresenta tal característica: vigem "sem precisar de fundamentação". Assim, além da autoridade baseada nos "fundamentos da razão", há outra maneira de determinar comportamentos e instituições. Nesse ponto se encontra o direito próprio da tradição. Eis a dívida "para com o Romantismo", de acordo com Gadamer.

Apesar de reconhecer tal dívida, Gadamer (2003, p. 373) não tarda a criticá-la também. O Romantismo incorre em outra "oposição abstrata", inversa, mas estruturalmente idêntica à oposição da Aufklärung entre razão e autoridade. A tradição seria algo contrário à autodeterminação racional, algo cuja influência se exerceria espontaneamente sobre as pessoas. Ou seja, as forças às quais se sub- 
mete quem participa de uma tradição se assemelham às forças naturais a que se sujeita um corpo físico qualquer. A força da razão, em contrapartida, proviria de outra fonte: da "autodeterminação livre" - capaz de resistir, inclusive, às forças "naturais" da tradição. Logo, o Romantismo também acaba contrapondo a razão à autoridade da tradição.

Por fim, Gadamer mostra por que a tradição não se opõe à razão:

Parece-me, no entanto, que entre a tradição e a razão não existe nenhuma oposição que seja assim tão incondicional. [...] Na realidade, a tradição sempre é um momento de liberdade e da própria história. Também a tradição mais autêntica e a tradição melhor estabelecida não se realizam naturalmente em virtude da capacidade de inércia que permite ao que está aí de persistir, mas necessita ser afirmada, assumida e cultivada. A tradição é essencialmente conservação e como tal sempre está atuante nas mudanças históricas. Mas a conservação é um ato da razão [...] (Gadamer, 2003, p. 373, grifos do autor).

Pois bem. A afinidade entre liberdade e tradição, para Gadamer, não é casual. O filósofo diz categoricamente: "a tradição sempre é um momento de liberdade" (Gadamer, 2003, p. 373). Todavia, ele parece titubear quando sugere, ao menos, duas modalidades de tradição. Uma seria "mais autêntica", da qual é logicamente possível deduzir outra "menos autêntica". O mais importante é o que o folósofo argumenta em seguida: em ambas as modalidades, a tradição não se impõe "por inércia", como crê o Romantismo, mas precisa ser "afirmada, assumida e cultivada", não importando se a tradição é "essencialmente conservação". Afinal, para conservar algo, é necessário reafirmá-lo, reassumi-lo. Ora, afirmar, assumir e cultivar algo são atividades típicas de quem exercita a razão, certo?

Mas não se trata de um ato qualquer da razão, pois não atrai "a atenção sobre si”, conforme Gadamer complementa em seguida:

Mas a conservação é um ato da razão, e se caracteriza por não atrair a atenção sobre si. Essa é a razão por que as inovações, os planejamentos aparecem como as únicas ações e realizações da razão. Mas isso não passa de aparência. Inclusive quando a vida sofre suas transformações mais tumultuadas, como em tempos revolucionários, em meio à suposta mudança de todas as coisas, do antigo conserva-se muito mais do que se poderia crer, integrando-se com o novo numa nova forma de validez. Em todo caso, a conservação representa uma conduta tão livre como a destruição e a inovação (Gadamer, 2003, p. 373-374, grifo do autor).

Enfim, aqui se concluem as arguições de Gadamer em favor da compatibilidade entre razão e autoridade. Justamente porque não atrai a atenção sobre si, a tradição conserva muitas coisas em períodos de grandes transformações. De fato! Transformações sempre saltam aos olhos, enquanto costumes já vigentes passam despercebidamente; novidades sempre chamam a atenção, ao passo que ninguém

2 Não é preciosismo, pois, no original, Gadamer usa stets. Cf. Gadamer (1999, p. 286). 
nota o que já lhe é familiar. Apesar de ser bastante eloquente, é uma afirmação extremamente rica em consequências para quem desconfia dos argumentos de Gadamer. Nesse aspecto é fundamental examinar cuidadosamente um ponto: a imperceptibilidade típica da conservação coere com a conscientização crítica, tão própria à liberdade da razão?

\section{CRÍTICAS DE HABERMAS AO CONCEITO DE AUTORIDADE}

Nesta seção convém examinar os argumentos de Gadamer contra a "oposição abstrata" entre autoridade e razão. Para respeitar a ordem da exposição de Gadamer, primeiro será tratada a autoridade da pessoa e, só então, a autoridade da tradição. Quanto à autoridade da pessoa, concentrar-se-á, basicamente, em uma observação crítica de Habermas (1990). Embora a análise seja rica em consequências, o folósofo não lhe dá a devida atenção em $A$ lógica das ciências sociais. Quanto à autoridade da tradição, dedicar-se-á a aprofundar e desenvolver a crítica de Habermas segundo a qual Gadamer teria cometido uma falácia. Em ambas as críticas há um ponto em comum: a hermenêutica enfraquece o poder da reflexão ao defender a convergência entre autoridade e conhecimento.

\section{AUTORIDADE DA PESSOA}

Em princípio, Habermas (1990) se esforça para contradizer o cerne da proposição de Gadamer: nada impede a autoridade de ser também "uma fonte de verdade". Logo, eis o problema, essa proposição não se oporia, necessariamente, à razão. Habermas considera uma "sentença maximamente dura" a conclusão de Gadamer, segundo a qual autoridade coere com conhecimento, não com obediência. Mas onde, afinal, estaria a dureza da conclusão de Gadamer? Até onde se pôde compreendê-lo neste artigo, Habermas assim a caracteriza, porque, em geral, a conclusão de Gadamer enfraquece o "poder da reflexão". Nessa questão se encontra o ponto de divergência entre ambos os filósofos. Para mostrar como a reflexão se enfraquece, Habermas examina o exemplo da autoridade do professor.

O filósofo procura mostrar como o professor é aquele pelo qual a tradição realiza o que lhe convém - a transmissão de preconceitos (Habermas, 1990, p. 254). Como ele argumenta, Gadamer visa a um processo de formação pelo qual a tradição se transforma em "procesos de aprendizaje individuales" e "objeto de apropriación". Para realizar tal apropriação, um professor inculca nos estudantes preconceitos herdados da tradição quando se encarrega de transmiti-la. E como o faz? Aí está a importância decisiva da autoridade. O professor encarna o modelo com o qual os estudantes se identificam e, assim, se estabelece entre esses sujeitos uma relação de autoridade. Por meio da autoridade se torna possível a "interiorización de normas", a "sedimentación de prejuicios".

Mas o que Habermas compreende por autoridade da pessoa é exatamente o que ele não desenvolve suficientemente. Todavia, se trata justamente de algo rico em consequências para quem se dispõe a criticar Gadamer. 
Para Habermas, a autoridade da pessoa, em tal caso, não pode significar conhecimento. "Por más vueltas que le demos, [autoridade] quiere decir: amenaza potencial de sanciones y mediante la perspectiva de gratificaciones" (Habermas, 1990, p. 254). Convém notar também que não há erro lógico no argumento de Habermas; ele não refuta só um exemplo, deixando intacto o argumento geral de Gadamer ${ }^{3}$. Pelo exemplo da educação, Habermas enfatiza aspectos da ideia mesma de autoridade, que se revelam mais claramente quando Gadamer usa exemplos.

Isso é o que transparece quando Gadamer precisa reconhecer a implicação entre autoridade e obediência, embora tivesse acabado de desvinculá-las ${ }^{4}$. Então, ele evoca, dentre outros, o exemplo do educador. Não seria inócuo reconhecer o educador como alguém dotado de mais conhecimento, só porque tal reconhecimento ocorre racionalmente. Reconhecê-lo como autoridade significa lhe conceder certo poder sobre mim. Por consequência, entre nós, já não há mais uma relação equânime, e sim uma bierarquia. A partir de então, aquele em relação ao qual me reconheço submisso pode constranger a qualquer momento a minha capacidade de ajuizar. Sim, a autoridade enfraquece a reflexão, pois constrange, ameaça a capacidade de criticar 5 .

Resta averiguar se a expectativa de gratificação, outro aspecto evocado na crítica de Habermas, também caracteriza a autoridade da pessoa. No caso particular do professor, parece claro, pois the cabe definir as notas dos estudantes nos registros da instituição. Mas, também sob uma perspectiva geral, a autoridade da pessoa suscita tal expectativa. Basta considerar quão gratificante tende a ser quando alguém concorda com uma autoridade ${ }^{6}$. A discordância, ao contrário, tende a ser um incômodo, uma tensão, um desconforto. Porém, a concordância pressupõe a abdicação da dúvida, virtude da reflexão, e o reforço de preconceitos. Logo, a expectativa de gratificação, que uma autoridade tende a induzir nos outros, acaba enfraquecendo a reflexão.

Até aqui, este artigo buscou examinar a autoridade no intuito de permanecer no âmbito estrito da pessoa. Para tanto, foi preciso abstrair um aspecto importante do reconhecimento da autoridade de alguém: a mediação de instituições. Um professor só dispõe do direito de ameaçar com sanções e encorajar com gratificações

3 É o que Schopenhauer (2003, p. 180) chama de "tomar a prova pela tese". Alguém poderia alegar: "ora, Habermas refuta apenas um exemplo particular, o que não desdiz a tese geral de Gadamer". Mas não é o caso aqui, como se procura demonstrar.

4 Não por acaso, Gadamer não consegue desvincular, em geral, autoridade de obediência, restando-lhe apenas desvinculá-la de um gênero mais extremo: a obediência cega.

5 Hierarquia explícita nas expressões "estar acima de" ou "ter primazia sobre", aspectos do que Gadamer (2003, p. 371) considera a "essência da autoridade". Ambas as expressões traduzem überlegen sein e den Vorrang haben, respectivamente. Cf. Gadamer (1999, p. 284).

6 Até a lógica (Copi, 1979, p. 81) considera legítimo o apelo à autoridade de alguém quando se é reconhecidamente competente no assunto. 
porque uma instituição lhe concede ${ }^{7}$. Ser professor não designa uma posição em um diálogo aberto, como Gadamer parece supor, mas, sim, uma posição dotada de certos poderes. É o que Habermas subentende em suas críticas a Gadamer. Assim, a pessoalidade da autoridade começa a se diluir na anonimidade de algo mais amplo. Esse aspecto é o que deve ser desenvolvido no próximo tópico, quando se passa a tratar da autoridade da tradição.

\section{AUTORIDADE DA TRADIÇÃO}

Convém examinar mais atentamente um comentário de Habermas, que, dada sua brevidade, pode passar despercebido: "Gadamer transforma el descubrimiento de la estructura de prejuicios del Verstehen en una rehabilitación de prejuicios como tal" (Habermas, 1990, p. 254). "Pero", ele pergunta, " ¿de la inevitabilidad de la anticipación hermenéutica se sigue eo ipso que haya prejuicios legitimos?”. Pois bem. Primeiro, o filósofo observa: Gadamer transforma uma coisa em outra - a descoberta da estrutura dos preconceitos da compreensão $\mathrm{em}$ uma reabilitação dos preconceitos. Habermas denuncia um equívoco e, então, o esclarece na forma de pergunta: da inevitabilidade da antecipação hermenêutica decorre a existência de preconceitos legítimos?

Qual seria o problema? Uma coisa é a descoberta da estrutura preconceituosa da compreensão, algo imposto, necessariamente, a qualquer um. Entretanto, outra coisa é a legitimidade dos preconceitos, algo meramente contingente. Afinal, "legítimo" e "ilegítimo" são valores e, enquanto tais, podem ou não ser atribuídos a uma coisa. Logo, da necessidade de a compreensão ser estruturalmente preconceituosa, não decorre a necessidade de os preconceitos da compreensão serem legítimos! Enfim, trata-se da "falácia naturalista", bem debatida na filosofia ${ }^{8}$. Gadamer falaciosamente, segundo Habermas (1990), deduz um valor de um fato, deduz a legitimidade dos preconceitos do fato de a estrutura da compreensão ser preconceituosa.

Habermas não cita, expressamente, o ponto no qual Gadamer teria cometido a falácia, mas há uma passagem de Verdade e método na qual essa falácia realmente ocorre. Primeiro, Gadamer se refere à inevitabilidade da adoção de costumes. Um fato! Disso, porém, ele deduz, despercebidamente, outra coisa, sua validade:

A realidade dos costumes, por exemplo, é e continua sendo, em sentido amplo, algo válido a partir da herança histórica e da tradição. Os costumes são

7 Para Gadamer (2003, p. 371), a autoridade não pode derivar de outorga. Claro! Afinal, a outorga de autoridade pode ser arbitrária e, portanto, destituída de razão. Mas me parece difícil desvincular autoridade e outorga no exemplo do professor. Em seu conteúdo, sua autoridade até pode resultar do reconhecimento racional. Em sua forma, porém, ela não pode prescindir da outorga. Afinal, um professor, por outorga, dispõe de certas prerrogativas de que os estudantes, por exemplo, não podem dispor.

8 Decerto, é difícil definir a falácia naturalista. Para Hume (2001, p. 509), ela consiste na tendência a deduzir do fato de uma coisa ser que ela deva ser assim. Para Brito (2010), tal equívoco não coincide com o que, mais tarde, Moore $(1903, \S 10)$ denominou "falácia naturalista”. Porém, Chediak (2006) apresenta uma interpretação que permite tratar o argumento de Gadamer como exemplo de tal falácia. 
adotados livremente, mas não são criados nem fundados em sua validade por um livre discernimento. É isso, precisamente, que denominamos tradição: ter validade sem precisar de fundamentação (Gadamer, 2003, p. 372, grifos do autor).

Quanto ao segundo ponto crítico desta seção, é muito mais uma transição do primeiro para o terceiro ponto. Aqui, cabe desemaranhar a relação confusa, introduzida na sequência da passagem anterior, entre Gadamer e o Romantismo. Por um lado, Gadamer concorda com o Romantismo: a tradição é realmente uma força anônima. Por outro lado, a tradição não pode agir "por inércia", pois assim se incorporaria ao comportamento humano e, furtivamente, lhe negaria a liberdade para se autodeterminar. Como nada haveria fora do âmbito de influência da tradição, não resta alternativa para a razão senão se conciliar com a tradição. Logo, Gadamer se obriga a encontrar uma característica comum em ambas, que só poderia ser a liberdade.

Não por acaso, o filósofo conclui: "a tradição sempre é um momento de liberdade", aquela mesma liberdade tão própria à autodeterminação da razão. Porém, eis o problema: a tradição, por ser conservação anônima, exigiria uma racionalidade muito peculiar; precisaria, sim, ser afirmada, assumida e cultivada - atividades tipicamente racionais, como sugere Gadamer. Mas é necessário fazê-lo anonimamente, sem "atrair a atenção sobre si”. Ora, bem nesse ponto, Gadamer se enreda em uma aporia decorrente de compromissos opostos. Ele pretende reconhecer sua "dívida" e, ao mesmo tempo, romper com o Romantismo. Entretanto, só há um nível, aparentemente, no qual a compreensão humana pode agir sem chamar a atenção: no inconsciente. Justamente no qual a razão se cala.

Enfim, o terceiro ponto: como a autoridade da tradição se firmaria em um reconhecimento racional? A vulnerabilidade do argumento de Gadamer se encontra,, na suposição segundo a qual a razão poderia agir sem "atrair a atenção sobre si”. Metodologicamente, claro, seria importante expor primeiro o que Gadamer compreende por razão. Todavia, o esmero conceitual não é uma característica de Gadamer, ao contrário de filósofos como Heidegger ${ }^{9}$. Uma oportunidade, por exemplo, teria sido o discurso intitulado Sobre o poder da razão, no qual a razão figura como tema principal. Mas Gadamer (2001, p. 41) não passa de considerações bastante vagas. Nenhuma de suas observações esclarece como a razão poderia agir sem atrair a atenção sobre si.

Seja como for, é necessário compreender bem a pergunta feita anteriormente. A tradição não é o que reconhece, mas, sim, o que está sendo reconhecido como autoridade. Em si mesma, portanto, não é aquilo que detém a racionalidade necessária ao reconhecimento. Racional deve ser, sim, quem a afirma, a cultiva, a

9 Há textos de Gadamer (2007a; 2007b) em cujos títulos a razão figura como tema, em particular, aqueles publicados em Hermenêutica em retrospectiva. Mas nem em Os limites da razão histórica nem em Razão e filosofia prática Gadamer desenvolve algo mais profundo. Exemplo de elaboração conceitual da razão é o que Heidegger (1999, p. 149) apresenta na décima terceira aula de $O$ princípio do fundamento. 
assume. Então, quem realiza tais atividades? Bom, uma resposta fácil: cada pessoa herdeira de uma tradição. Assim, Gadamer se livra do problema de atribuir racionalidade a algo anônimo como uma sociedade. No entanto, não é possível evitar outra questão também desconcertante. Como as atividades de afirmar, cultivar e assumir podem ser racionais e, ao mesmo tempo, por serem conservadoras, não atrair a atenção sobre si?

Assim, retorna o problema do segundo ponto crítico. Em um nível inconsciente, ou mesmo subconsciente, a compreensão humana pode agir sem chamar a atenção. Nesse nível, porém, a razão se cala. Alternativamente, é possível afirmar, cultivar e assumir uma tradição por inércia. Mas, justamente assim, o Romantismo acabou sustendo outra "oposição abstrata" entre a autodeterminação racional e a autoridade da tradição, ponto crítico para Gadamer. Em suma, a racionalidade só parece agir conscientemente e não pode fazer outra coisa senão chamar a atenção sobre si. Destituída de razão, a autoridade da tradição se vê fatalmente exposta ao problema da violência. É precisamente ao que Habermas (1990) visa em suas críticas a Gadamer:

El prejuicio de Gadamer en favor del derecho de los prejuicios acreditados por la tradición pone en cuestión la fuerza de la reflexión, fuerza que por su parte se acredita en su capacidad de poder también recusar la pretensión de las tradiciones. La sustancialidad se derrite en la reflexión, porque ésta no siempre confirma sino que también quiebra los poderes dogmáticos. Autoridad y conocimiento no convergen. Verdad es que el conocimiento está enraizado en la tradición fáctica; permanece ligado a condiciones contingentes. Pero la reflexión no opera sobre la facticidad de las normas recibidas sin dejar huella. Está condenada a iniciarse post factum, pero al mirar hacia atrás, desarrolla también una fuerza retroactiva. Sólo podemos inclinarnos sobre las normas interiorizadas tras haber aprendido a seguirlas ciegamente bajo un poder impuesto desde fuera. Pero la reflexión, al traer a la memoria y poner ante ella esa vía de autoridad por la que fuimos dogmáticamente ejercitados en las gramáticas de los juegos de lenguaje como reglas de la comprensión del mundo y de la acción, puede despojar a la autoridad de aquello que en ella no era más que dominio y disolverla en la coacción bastante menos coactiva que representan la intelección y la decisión racional (Habermas, 1990, p. 255).

Nesse aspecto, é necessário desenvolver melhor um ponto: a diferença de temporalidade entre autoridade e reflexão racional. "[A reflexão] está condenada a se iniciar post factum, mas, ao olhar para trás, desenvolve também uma força retroativa" (Habermas, 1990, p. 255). De fato, a reflexão só ocorre depois de a autoridade já ter sido conquistada. Enquanto a razão lida com coisas presentes, a autoridade vive do reconhecimento passado. Eis por que a autoridade da tradição, uma vez difundida e inculcada, tende a agir "por trás", sem "chamar a atenção sobre si". Assim, a temporalidade da reflexão é o presente, pois exercita sua capacidade crítica em algo manifesto. Já a temporalidade da autoridade é o passado, pois vive de um reconhecimento obtido outrora. 
Proveniente do passado, a autoridade almeja preservar uma posição que, uma vez conquistada, não deseja ser posta à prova. A razão, ao contrário, vive muito mais de um exercício decidido caso a caso. Afinal, a dúvida, principal instrumento da razão, incide sempre sobre questões pontuais. Ora, bem aí se encontra o descompasso entre autoridade e razão, pois o que uma busca a outra recusa. Não por acaso, a educação constantemente se envolve em um paradoxo: enquanto instituição, deseja preservar a estabilidade outrora conquistada. Porém, enquanto experiência, deseja promover a liberdade de cada manifestação de pensamento. Ora, o que é estável, por definição, tende a se opor ao que é livre. Logo, autoridade não combina com razão.

\section{RESPOSTAS DE GADAMER}

No ensaio Retórica, hermenêutica e crítica de ideologia, Gadamer apresenta respostas a algumas críticas de Habermas apresentadas em A lógica das ciências sociais. Mas, ao invés de uma defesa cuidadosa, Gadamer diz tudo o que parece considerar necessário em cerca de duas páginas. Assim, deter-se-á em pontos a partir dos quais, aparentemente, poderiam ser desenvolvidos contra-argumentos às críticas feitas até aqui. Em um primeiro momento, esforçar-se-á para ser tão fiel quanto possível à perspectiva de Gadamer. A princípio, parece importante notar a posição prévia da qual o filósofo parte antes de responder propriamente a Habermas. Gadamer (2004, p. 284) considera "algo evidente" desvincular autoridade e razão da "antítese abstrata do Iluminismo".

Então, o filósofo se justifica:

A antítese abstrata do Iluminismo parece-me ignorar algo de verdadeiro, e isso tem consequências funestas. Isso talvez ocorra porque se atribui um falso poder à reflexão, ignorando por motivos ideológicos as verdadeiras dependências. Supondo-se, é claro, que a autoridade exerça um poder dogmático seguindo uma infinidade de formas de domínio, desde as instituições de ensino, passando pelos comandos do exército e do governo até a hierarquia do poder político ou das autoridades religiosas. Mas essa imagem de obediência que se presta à autoridade jamais poderá mostrar por que motivo todas essas instituições são ordens e não a desordem de um despotismo do poder (Gadamer, 2004, p. 284, grifo do original)

Primeiro, é bom notar, o filósofo parte de uma suposição. O filósofo propõe que se suponham várias instituições baseadas em um "poder dogmático", estruturado em uma "infinidade de formas de domínio". Então argumenta que subjaz aí uma "imagem de obediência", que o Iluminismo - e também Habermas - atribui à autoridade. Porém, tal "imagem de obediência" não consegue mostrar uma coisa importante. Por que tais instituições resultam em uma ordem, ao invés de uma desordem, típica do despotismo? Se as instituições se baseassem em um "poder dogmático", conforme a suposição proposta inicialmente, deveriam promover a desordem. Em outras palavras, a ordem das instituições, segundo Gadamer (2004),deveria ser uma "evidência" da sua constituição racional. 
Creio serem razões indubitáveis que levam a afirmar que é importante reconhecer as verdadeiras relações de autoridade. Podemos perguntar: em que se baseia esse reconhecimento? De certo «sic , essa autoridade poderia, muitas vezes, também expressar uma real submissão impotente frente ao poder. Mas isso não é reconhecimento nem se baseia na autoridade. Basta estudarmos casos de perda e decadência (e o contrário disso) para ver o que é e de que vive. Não vive do poder dogmático, mas do reconhecimento dogmático. E o reconhecimento dogmático não é nada mais que atribuir à autoridade uma superioridade no conhecimento, acreditando por conseguinte que ela tenha razão. É seu único "fundamento". Ela domina, portanto, porque é "livremente" reconhecida. A obediência que se lhe tributa não é cega (Gadamer, 2004, p. 284-285)

As razões apresentadas na passagem anterior seriam “indubitáveis", segundo o filósofo, para "reconhecer as verdadeiras relações de autoridade". Assim, é possível deduzir, as verdadeiras se baseiam no "reconhecimento dogmático"; as falsas, no "poder dogmático", na "submissão impotente" - elas, sim, dignas das críticas de Habermas. Mas o que significa "reconhecimento dogmático"? Gadamer responde: "[...] Não é nada mais que atribuir à autoridade uma superioridade no conhecimento, acreditando por conseguinte que ela tenha razão" (Gadamer, 2004, p. 284-285). De fato, quando a autoridade domina, as pessoas the rendem obediência, Gadamer o reconhece. Não se trataria de obediência cega, como pensa o Iluminismo, mas, sim, de obediência "livremente' reconhecida".

Portanto, as críticas de Habermas se dirigem a outra espécie de autoridade, aquela que, para Gadamer, é simplesmente falsa. Eis a razão pela qual o filósofo não compreende por que Habermas o critica. Para ele, conforme observa no fim da seguinte passagem, ambos defendem posições, no mínimo, semelhantes:

É inadmissível, porém, a suposição de que eu estaria afirmando hão haver perda de autoridade e crítica emancipatória. [...] A afirmação de que a tradição deveria ser e continuar sendo a única base para justificar preconceitos, como me atribui Habermas, contradiz a minha tese de que a autoridade repousa no reconhecimento. Quem alcançou a maioridade pode - mas nãoé obrigado a - acatar, pelo saber, o que aceitava pela obediência. A tradição não representa nenhuma garantia, não, pelo menos, onde a reflexão exige uma garantia. Mas essa é a questão: Onde é que o exige? Em tudo? [...] Trata-se de saber se devemos estabelecer a função da reflexão do lado da conscientização, que confronta o vigente com outras possibilidades, rechaçando o estabelecido em favor dessas outras possibilidades, mas podendo também assumir conscientemente o que oferece de fato a tradição, ou se a conscientização sempre e somente dissolve o vigente. Quando Habermas afirma que se pode "retirar da autoridade aquilo que nela era mera dominação (interpreto: o que não era autoridade), podendo ser dissolvido de forma não violenta pelo saber e pela decisão racional", já não sei por que estamos ainda discutindo. (Gadamer, 2004 , p. 285, grifo do autor). 
Depois da maturidade, já não há obrigação, Gadamer afirma, de acatar o que antes tinha sido aceito por obediência. Então, o filósofo se questiona: quando a reflexão deve exigir da tradição "uma garantia" do que ela lhe legou? A resposta precisa partir da diferença entre duas funções da reflexão. Primeiro, o que Gadamer defende, uma conscientização capaz de confrontar, mas também de conceder razão à tradição. Segundo, o que Habermas estaria defendendo, uma conscientização para quem a tradição seria "sempre e somente" algo a ser desfeito. Ora, se Habermas considera possível purgar a autoridade do que nela é dominação, ele também deve supor uma forma racional de autoridade. Logo, Gadamer conclui que o debate realmente perde o sentido.

Assim expostos, os argumentos de Gadamer parecem ser mesmo bem razoáveis. Mas há algo importante na crítica de Habermas que Gadamer não considera seriamente. Trata-se do aspecto característico da autoridade de um educador: a prerrogativa de ameaçar com sanções ou estimular com gratificações. Um ponto crítico pelo qual é possível mostrar como a autoridade - tal como $\mathrm{Ga}$ damer a compreende! - coíbe a razão. "Superioridade no conhecimento", para usar as palavras de Gadamer, envolve analiticamente hierarquia. Uma vez instaurada, uma hierarquia, necessariamente, inibe a possibilidade de um exercício pleno da liberdade! Afinal, a liberdade supõe antes relações horizontais — para ser mais claro, relações sem hierarquia!

Ademais, é duvidosa a liberdade atribuída ao reconhecimento da autoridade das instituições. Sim, primeiro, elas impõem autoridade pela obediência. Depois, na maturidade, Gadamer diria, já não haveria obrigação de aceitá-las. É mesmo? Uma vez estabelecidas, as instituições instauram uma dinâmica de poder, cuja força política extrapola a força crítica de qualquer um; mais especificamente, um nexo de relações cuja estrutura Foucault (2001, p. 14; 2009) chama de "regime de verdade”. Em tal situação, não é possível supor, tão ingenuamente, relações livres de coerção. Mesmo na maturidade, não é nada trivial simplesmente negar sua ordem! Logo, para Gadamer, essas relações se tornaram falsas? O que nelas restaria de "verdadeira autoridade"?

Para concluir, a autoridade verdadeira deveria dispensar o que a define, segundo Gadamer: a superioridade de conhecimento. Em uma das passagens supracitadas, Gadamer admite a possibilidade de perda de autoridade. Se há risco de perdê-la, então a autoridade precisa se reafirmar caso a caso. Tal dependência de cada ocasião subverte a temporalidade do que confere sentido à autoridade: o respeito antes suscitado. $\mathrm{O}$ que realmente deveria importar são as razões apresentadas a cada instante, a despeito de qualquer status conquistado anteriormente. Logo, para que conferir superioridade a alguém ou à tradição? - Afinal, aquilo com o qual eles devem coerir para serem verdadeiras autoridades, a razão, não vive no passado, mas, sim, no presente.

Enfim, tratar qualquer coibição como algo alheio à "verdadeira essência da autoridade" implica ignorar um problema fundamental para a educação. A autoridade supõe uma hierarquia na qual a consequência é o enfraquecimento da razão. Uma vez submetida a uma relação hierárquica, a razão se torna invariavelmente suscetível à complacência. A priori, está posta uma relação: o professor sabe, enquanto eu não sei. 
Não por acaso, a educação formal frequentemente se debate com um paradoxo difícil de desfazer. Enquanto instituição, impõe a ordem derivada da autoridade. Porém, enquanto experiência, se considera livre. Como conclusão deste ensaio acrescenta-se: não parece possível conciliá-las. Então, qual delas? Aqui, escolhe-se a liberdade.

\section{REFERÊNCIAS}

BRITO, A. N. Falácia naturalista e naturalismo moral: do é ao deve mediante o quero. Kriterion, Belo Horizonte, v. 51, n. 121, p. 215-226, 2010. https://doi.org/10.1590/ S0100-512X2010000100011

CHEDIAK, K. O problema da falácia naturalista para o projeto de uma ética evolucionista. Kriterion, Belo Horizonte, v. 47, n. 113, p. 147-157, 2006. https://doi. org/10.1590/S0100-512X2006000100008

COPI, I. Introdução à lógica. 2. ed. São Paulo: Mestre Jou, 1978.

FOUCAULT, M. Microfísica do poder. 16. ed. Rio de Janeiro: Graal, 2001.

FOUCAULT, M. A ordem do discurso: Aula Inaugural no Collège de France, pronunciada em 2 de dezembro de 1970. 19. ed. São Paulo: Edições Loyola, 2009.

GADAMER, H.-G. Gesammelte Werke 1: Hermeneutik I.Tübingen: Mohr Siebeck, 1999. Aufl. 6.

GADAMER, H.-G. Elogio da teoria. Lisboa: Edições 70, 2001.

GADAMER, H.-G. Verdade e método I: traços fundamentais de uma hermenêutica filosófica. 5. ed. Petrópolis: Vozes; Bragança Paulista: Universitária São Francisco, 2003. GADAMER, H.-G. Verdade e método II: complementos e índice. 2. ed. Petrópolis: Vozes; Bragança Paulista: Universitária São Francisco, 2004.

GADAMER, H.-G.Hermenêutica em retrospectiva. Rio de Janeiro: Vozes, 2007a.v. II. GADAMER,H.-G.Hermenêutica em retrospectiva. Rio de Janeiro: Vozes, 2007b.v.III. HABERMAS, J. La lógica de las ciencias sociales. 2. ed. Madrid: Tecnos, 1990.

HEIDEGGER, M. O princípio do fundamento. Lisboa: Instituto Piaget, 1999.

HUME, D. Tratado da natureza humana. São Paulo: Editora UNESP; Imprensa Oficial do Estado, 2001.

MOORE, G. Principia ethica. New York: Prometheus Books, 1903. Disponível em: http://fair-use.org/g-e-moore/principia-ethica. Acesso em: 8 abr. 2019.

SCHOPENHAUER, A. Como vencer um debate sem precisar ter razão: em 38 estratagemas - dialética erística. Rio de Janeiro: Topbooks, 2003.

\section{SOBRE O AUTOR}

RAINRI BACK é doutor em filosofia pela Universidade do Estado do Rio de Janeiro (UERJ). Professor de Universidade de Brasília (UnB). E-mail: rainri.back@yahoo.com.br 
Conflitos de interesse: $\mathrm{O}$ autor declara que não possui nenhum interesse comercial ou associativo que represente conflito de interesses em relação ao manuscrito.

Financiamento: $\mathrm{O}$ estudo não recebeu financiamento.

Recebido em $1^{\circ}$ de maio de 2020

Aprovado em 9 de março de 2021 